\title{
Drawing Conclusions
}

\section{Supporting Decision Making through Collaborative Graphic Annotations}

\section{A Classification of Sketchmarks}

\author{
Martin J. Eppler \\ Roland Pfister
}

July 2010

To cite this paper:

Eppler, M.J., Pfister, R. (2010) Drawing Conclusions: Supporting Decision Making through Collaborative Graphic Annotations - A Classification of Sketchmarks. $=m c m$ working paper, No. 1/2010, July 2010. St. Gallen: $=\mathrm{mcm}$ institute, University of St. Gallen. [Retrieved online at: www.knowledge-communication.org] 


\title{
Drawing Conclusions
}

\section{Supporting Decision Making through Collaborative Graphic Annotations A Classification of Sketchmarks}

\section{Martin J. Eppler, Roland Pfister}

\begin{abstract}
:
Although the application of sketch-based chart annotation is not pervasive in management, the use of sketchmarks can provide numerous benefits to managerial discussions. The collaborative use of chart annotations can support management teams in their decision making based on quantitative charts by visually eliciting and capturing interpretation processes, clarifying basic assumptions, stimulating different perspectives, and extrapolating trends into the future. Sketch-based annotations combine the simplicity and immediacy of drawing with the clarity and richness of charting. In this paper, we provide the rationale for this under-researched visual management and communication practice, illustrate it through examples, and - as our main contribution - provide a first overview classification of the different sketchmarks that management groups can use in their discussion of quantitative charts (for such contexts as strategy or project reviews). In the end of the working paper we briefly describe our future research in this area and highlight implications for management. We provide basic sketchmark forms and guidelines for managers and facilitators in the appendix.
\end{abstract}

Keywords: decision making, decision support, management meetings, charting, sketching, chart annotation, decision quality, sense making, sketchmark, communication quality, research

\section{Outline:}

1. Introduction and Overview

2. Benefits of Sketching and Sketch-based Chart Annotation

3. Examples of Sketch-based Chart Annotation in Management

4. A Classification of Sketchmarks in Chart Annotation

5. Conclusion and Outlook

References

Appendix:

Table 1: Examples of sketchmarks for use in management meetings

Table 2: Guidelines for the use of sketchmarks in management meetings 


\section{Introduction and Overview}

Simplicity is the highest level of sophistication. Leonardo da Vinci

Quantitative Charts such as portfolio diagrams, bar, line or pie charts often form the basis for management decisions - for example in the context of strategy or project reviews. Such quantitative charts are often discussed in management teams based on a prior slideshow presentation or a printed report. In the ensuing discussions, however, managers may detach themselves from the presented or reported data and revert to their own experience or prior opinions instead of focusing on the presented data and their meaning and implications. Another frequent challenge of such meetings consists of creating a collaborative atmosphere and coming to a truly shared understanding of a strategy or a project portfolio. Many managers also struggle to fully capture their deliberations and argumentations for subsequent meetings or follow-up decisions.

An alternative, often more effective way to support such decision and communication processes consists of giving managers the opportunity to jointly annotate the presented charts, either on a poster or flipcharts (or through a multi-touch large screen or an interactive whiteboard), thus literally working with the chart and using it as an inscription device (Henderson 1991) to capture their collective interpretations of the represented data and make the data's implications visible to everyone. Managers can make use of such simple sketchmarks to augment the quality of their group communication. Hence, the main concept introduced in this paper is the notion of sketchmarks or markups on diagrams using handdrawn sketches. We define a sketchmark in this context as follows: A sketchmark is a hand-drawn, simple, and ad-hoc annotation,
modification, or addition to one or several elements of a quantitative
or qualitative diagram on a poster, flipchart, piece of paper, or via a
digital pen on a tablet PC or interactive whiteboard. A sketchmark is
drawn during a conversation, usually in front of colleagues involved in
a joint decision or discussion process. Example:

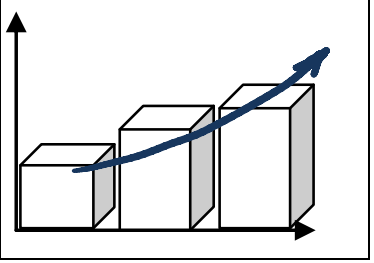

We believe that such sketchmarks will become a useful and pervasive management practice, as collaborative decision making approaches and the corresponding technology mature. Sketches, however, have so far mainly been discussed as creativity catalysts (see Verstijnen et al. 1998, MGown Gree, 1998, Anderson \& Helstrup 1993, Goldschmidt 1991, Duarte 2008) and not necessarily as analytic, collaborative thinking tools (for exceptions see Heiser et al. 2004 and Ferguson 1994).

In this article, we thus show how managers can use the power of provisionality and informality inherent in hands-on sketching, particularly when combined (super-imposed) with the data-rich format of quantitative charts. We give an overview on the different sketching actions and conventions that managers can exploit to add meaningful marks to 
numeric charts. The sketchmarks we used are intended to expand our visual vocabulary, always with the final goal in mind, to develop a truly, yet analytical way of expressing insights. In the next section, we discuss some of the main benefits of sketching on charts in management $^{1}$ (as identified by prior studies) and illustrate them through two simple and typical examples. This is followed by a classification of sketchmarks. In the conclusion we summarize the main points of the article and describe avenues for future research in this area. The appendix includes a table with examples of sketchmarks, as well as a table with managerial guidelines on how to best use annotative sketching during meetings and workshops.

\section{Benefits of Sketching and Sketch-based Chart Annotation}

The mind does not think without an image. Aristotle

Why should managers and organization scholars be interested in analytic sketching (as opposed to technical and artistic sketching ${ }^{2}$ )? One of the main reasons may be the high number of benefits that such sketching can provide for collaboration and decision making in management. These benefits have been discussed and demonstrated in various research projects on the topic of sketching, primarily in the areas of design, engineering and psychology. Below we review these benefits in more detail. We first focus on the benefits and advantages of sketching in general, and then focus more specifically on sketching as a collaborative annotation practice in management. ${ }^{3}$

Sketching in general, according to design theorist and practitioner Bill Buxton (2007, p. 105), can be considered a tool of thought that enables the mind to capture things which are in flux and iteratively refine them. Stanford psychologist and sketching expert Barbara Tversky also views sketches as thinking tools - individually and in groups (as do Fish \& Scrivener, 1990). In her numerous articles on the topic (such as Tversky \& Masaki 2009, Tversky et al. 2000, or

\footnotetext{
${ }^{1}$ The benefits of sketching on charts (and in free form) have already been discussed in the practitioner community regarding more effective client meetings in the sales context. This stream of thought is often referred to as "pencil selling" and has gained a lot of attention in sales management recently.

${ }^{2}$ This simple distinction is based on the application context and aim of a sketch, i.e., whether it is used in an artistic context and ultimately results in a work of art, or if it is used in a technical or engineering context to represent technical equipment or parts thereof. Analytic sketches, by contrast, may not represent physical artifacts, but rather depict conceptual, abstract structures, such as categories or concept labels, or add conceptual cues to existing diagrams or charts (as in the case of sketchmarks).

${ }^{3}$ Naturally, the practice of sketching also has disadvantages or risks that need to be taken into consideration. One such potential disadvantage may be the ambiguity of certain sketchmarks. Many symbols used in sketching are open to multiple interpretations and thus need to be clarified verbally. A case in point is the sketched arrow that may indicate a causal relationship, a chronological sequence, a loose connection or relation, or the extrapolation of a trend. This inherent ambiguity, however, can also be useful to trigger clarification dialogues, see Eppler et al. 2008. Another risk (inherent in any type of visualization) of sketching is reification or the premature fixing of a view or thought that should still be in flux. Nevertheless, sketches have what we call a low perceived finishedness (Bresciani et al. 2008) and thus invite changes and modifications more than other visualizations. There are also disadvantages related to the medium of sketching: sketches on paper are more difficult or cumbersome to modify than on screen for example (see Landay 1996, p.7, for this point).
} 
Tversky 2002), she emphasizes the speed of sketching, its provisional nature (before definitive commitments, in order to enable an 'expression of the vague'), and its simplicity as key benefits. In collaboration contexts, she and colleagues Heiser and Silverman (Heiser et al. 2004, p. 6) stress the following benefits of sketching: establishing a joint focus among conversers, promoting interactivity and involvement, fostering efficient and enjoyable collaboration, being conducive to creating shared meanings and leading to better listening and better memorability of the issues discussed. In their study, Tversky and her colleagues provide experimental and observational evidence for these benefits. Similarly, McGown and Green (1998) stress the following (collaborative) advantages of hand-drawn sketches: they are fast and seamless, easy to (re-) do, have an immediate effect, can trigger a high quality response, and they are highly expressive and only constrained by the drawer's imagination.

In a very different (but equally informative) domain, namely psychoanalysis, Mayer (2008) focuses on the use of sketches as a conversation and analysis catalysts among psychotherapists and their patients. The sketch in this context becomes a potentially unfiltered access point to the feeling and thoughts of a patient and lets the therapist and patient explore important themes or issues together (also over time, by using older sketches in subsequent sessions). Sketching in this context becomes a reflection enabler that gives the patient and the analyst access to previously unarticulated hopes, fears, or experiences. According to Mayer (2008, pp. 11-12) hand-drawn conceptual sketches in general provide the following advantages:

- They engage people and keep them focused and concentrated.

- They help to abstract or generalize from a concrete phenomenon or situation.

- They signal work in progress and subjective perspectives and consequently invite modifications or extensions.

- They invite the drawer to explore a change in perspective and view things differently.

- They help to articulate previously implicit notions or beliefs.

- They become an instant documentation for subsequent reference and later analysis and comparisons.

While sketching as a chart annotation practice is quite different from the aforementioned study contexts of engineering, group learning, or counseling, many of the described benefits can also be used in the application of sketchmarks. This is true for the individual (such as speed, change in perspective, or iterative refinement), as well as the collaborative advantages of sketches (joint focus and engagement, memorability, articulating assumptions etc.). In effect, annotating graphic charts can bring about numerous benefits that can ultimately lead to better communication and decision quality. As Twersky and Suwa point out (2009, p. 76): 
Sketches serve as an easy referent for words and gestures, so deictic expressions like here and there and this part and that way simultaneously make communication easier and more precise.

This is exactly what is happening when managers add sketchmarks to charts: By sketching on and pointing at the chart and by adding symbols or by connecting elements, managers make the implications of data visible and help their colleagues see and understand the consequences of the presented numbers.

But sketchmarks help to achieve much more than just a common focus. As meeting participants comment on each others' sketchmarks and remarks, they start to converge in their interpretation processes, clarify basic assumptions, stimulate different perspectives and extrapolate trends into the future. Through their playful, collaborative, and informal mode, sketches contribute to a truly open dialogue (Isaacs, 1997; Bohm, 2000) that is characterized by the suspension of one's own beliefs and assumptions and by an active engagement with the viewpoints of others. ${ }^{4}$

In summary, sketchmarks are a useful communication and decision making practice for managers because they offer advantages at the beginning of a meeting, during a meeting, towards the end of a meeting, and after a meeting.

A meeting supported by the use of sketchmarks follows a simple micro-process: At the beginning of the meeting sketchmarks can help to create an atmosphere of open dialogue and collaboration (see also Blackwell et al. 2008). Adding sketches can help managers focus their attention on a joint issue and really be in the moment (and not check their Blackberry for new messages instead). The advantage of sketchmarks is that the presenter and every participant has the possibility to emphasize figures, developments or points to focus on. Those accented deviations, anomalies etc. stay visible and top of all heads during all further steps of the meeting.

The next step in the meeting would be the phase, where the participants and especially the experts analyze the displayed information. Techniques such as extrapolating, resizing and tagging the charts support the analysis by adding additional information. All participants can play an active part as they are invited to draw on the slides and express their views. By capturing the participants' implicit knowledge graphically, the sketchmarks help to transform implicit into explicit knowledge and thereby make it accessible to all team members.

The evidence-based approach from Pfeffer and Sutton (2006) emanates from the believe, that managers can practice their craft more effectively, if they are routinely guided by the best logic and evidence and if they constantly seek new knowledge and insight, to keep

\footnotetext{
${ }^{4}$ In adding sketchmarks to charts, it can be useful to distinguish these different viewpoints visually, for example by giving differently colored pens to different meeting participants. Later on, however, it may be better to use color coding to differentiate different types of sketchmarks, such as interpretive marks versus action-oriented sketchmarks.
} 
updating their assumptions, knowledge and skills. Instead of just taking what is printed on the slide as the single source of information, they collaboratively complement the data and enrich the information content. The knowledge of every single participating team members gets incorporated and thus upgrades insights and may also rectify assumptions. Sketching therefore could be an important approach to tap the collective wisdom and experience of a team and a step away from eminence based management towards evidence bases management.

After having analyzed the discussion items and thus gained lots of additional information, the team members enter the discussion phase were the sketchmarks help to make communication more accurate by inviting managers to point at issues under discussion and label them explicitly. Sketching also fosters a data-driven mode of reasoning by forcing managers to refer to numbers in charts when making their contributions. It enables participants to articulate their basic assumptions and beliefs, and helps them express what they think or know and in doing so refine their reasoning.

Towards the end of the meeting, sketchmarks support the last step of the micro-process where they can facilitate a convergence in interpretation among a team of managers, and assist them in delineating a joint course of action, as well as securing commitments for these actions. Thus, the sketchmarks become decision catalysts.

After the meeting, finally, the sketchmarks result in an accessible and memorable documentation of the different viewpoints, interpretations, and judgments, as well as of decisions that were taken during the meeting.

Three short and realistic scenarios will illustrate a few of these benefits in the next section. Plus a box at the end of the next section illustrates how skethcmarks are used in a different kind of context, namely the military and its operations planning.

\section{Examples of Sketch-based Chart Annotation in Management}

The sketch is one of the most tangible artifacts produced directly by conceptual activity.

\section{Alistair McGown and Graham Green}

Below, we provide three short scenarios that can illustrate the use of sketchmarks in management discussions, as well as the ensuing benefits for a higher communication and decision quality in management teams:

\section{Scenario 1: A Cost Reduction Discussion in a Monthly Project Status Meeting}

Imagine yourself sitting in a monthly project status update meeting. As the project costs are getting out of hand, the focus of the meeting is on the analysis of the main cost drivers and on possible solutions. As usual, the project management officer has prepared a full deck of 
slides with stacked bar charts, showing the development of costs per month in various categories.

The main part of the status meeting, however, is dedicated to getting a common understanding of the underlying costs and discussing potential target areas for cost savings. After having presented lots of charts and figures, the presenter displays a bar chart, showing the development of the total costs over the last twelve months. Following the micro-process described above, they first start by highlighting and emphasizing certain values, months or upper-limits in order to draw the participants focus on those specific data points.

While discussing the cost development, an expert from the controlling department sketches on the bar chart with a red pen to highlight the increase of the cost base during the last quarter in order to emphasize abrupt rises or to relate two different months to each other. By dividing and hatching the columns, the participants gain an understanding of how the total costs add up and which cost categories are responsible for rising costs. They immediately see that substituting employees by contractors in the month of July has not reduced total costs, but rather lead to an abrupt bounce in general expenses. The expert also uses sketching to document cost saving activities that were implemented in March. This can be done by extending the bars of the months after those activities took place and helps to point out where they would stand nowadays, without those cost savings.

After the expert has given lots of insight on these figures and has brought all participants to the same level of understanding, the project manager identifies possible toeholds for cost savings. He uses a blue pen and extrapolates the cost curve for both scenarios. Those possible scenarios are also captured by sketching on the initial bar chart. In the following step, the participants have the possibility to vote whether they would prefer the approach to reduce personal expenses or rather keep those expenses on the same level and reduce general expenses instead. Each meeting participant leaves his vote as a small vertical line on the bar chart (at his or her preferred scenario).

In their project status meeting, the participants mainly use arrows to depict different possible future directions or the development of the costs, and circles to emphasize specific values. They furthermore extended curves, divided or resized the bars by enlarging or hatching them. To discuss the months May and November, which have a similar cost structure, they use connectors to show the relationship between those values. Very basic symbols as flashes, clocks or checkmarks are used to draw the participant's attention to a specific value or development. 


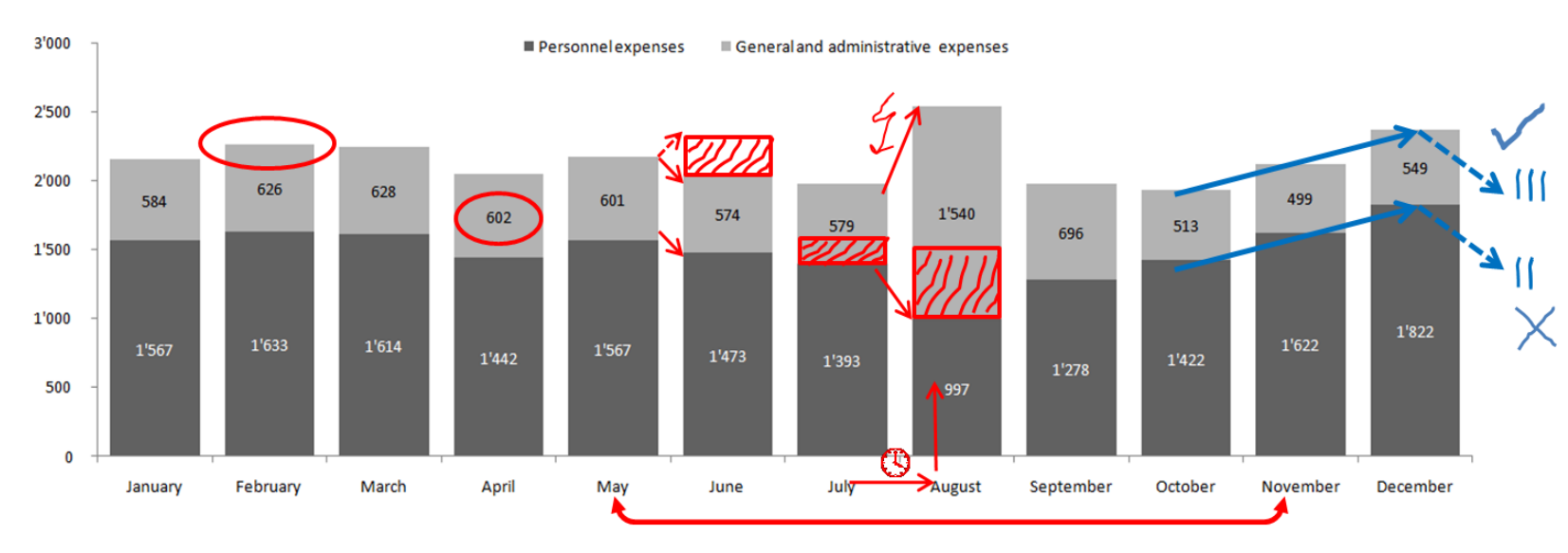

Figure 1: An example of sketchmarks on a project cost evolution chart

At the end of the meeting, the participants feel that they truly understand how the cost curve will develop and are confident that, based on the various discussed scenarios, they agree on the right decisions to bring the project to a, at least from a financial point of view, successful end.

For the follow-up meeting, the participants will again use the annotated bar charts to document the shift in costs since they have implemented their latest cost saving activities.

\section{Scenario 2: A Project Portfolio Review Meeting}

Imagine that you are part of a management committee that is reviewing the current project portfolio of the organization. To prepare the committee's discussion on which projects to cancel, modify, combine, or continue, a diagram has been developed to map all current projects. The projects in the diagram are positioned according to their current status with regard to budget (i.e., in line with budget, below it or exceeding it) and with regard to timing (i.e., on track, ahead or late). All 27 projects (see Figure 2) currently under way in the organization are thus positioned according to these two dimensions (time compliance and budget compliance). A third dimension that is mapped in the diagram is the project size which is represented by the bubble size in the diagram below.

The resulting visualization has been printed out on a large poster and has been mounted on a meeting wall for the committee's review workshop. Information on the individual 27 projects has been distributed to all committee members two weeks before the workshop. At the beginning of the workshop, each project is again quickly presented (larger projects receive more presentation time than smaller ones).

The main part of the review workshop, however, is dedicated to discussing the project portfolio diagram and the positioning of each project, as well as the implications for the corresponding funding decisions. While discussing the project portfolio and the individual projects, the participating managers sketch on the diagram to highlight the current focus of discussion, to group related projects, to emphasize their questions or comments, or to relate 
projects to each other. They also use sketching to document their joint decisions (for example by crossing out a project that will not receive further funding or reducing a project, such as number 26) and to introduce an additional decision criterion that came up during the discussion, namely the strategic relevance of each project (added as an $\mathrm{S}$ to each corresponding project bubble). During the discussion, the idea of an additional project emerges. This is also captured by sketching on the poster (project number 28).

In their joint sketching, the participants make use of simple icons, circles, and arrows to represent their joint interpretations and deliberations. The icons used in the example below are plus signs to designate excellent projects, question marks to indicate uncertainty or doubts, a hurray person to indicate achievements (projects 13 and 14), or dotted arrows to indicate possible future developments (for example for project 25). Arrows assume different meanings (that need to be made explicit in the discussion), such as dependences, causes or changes.

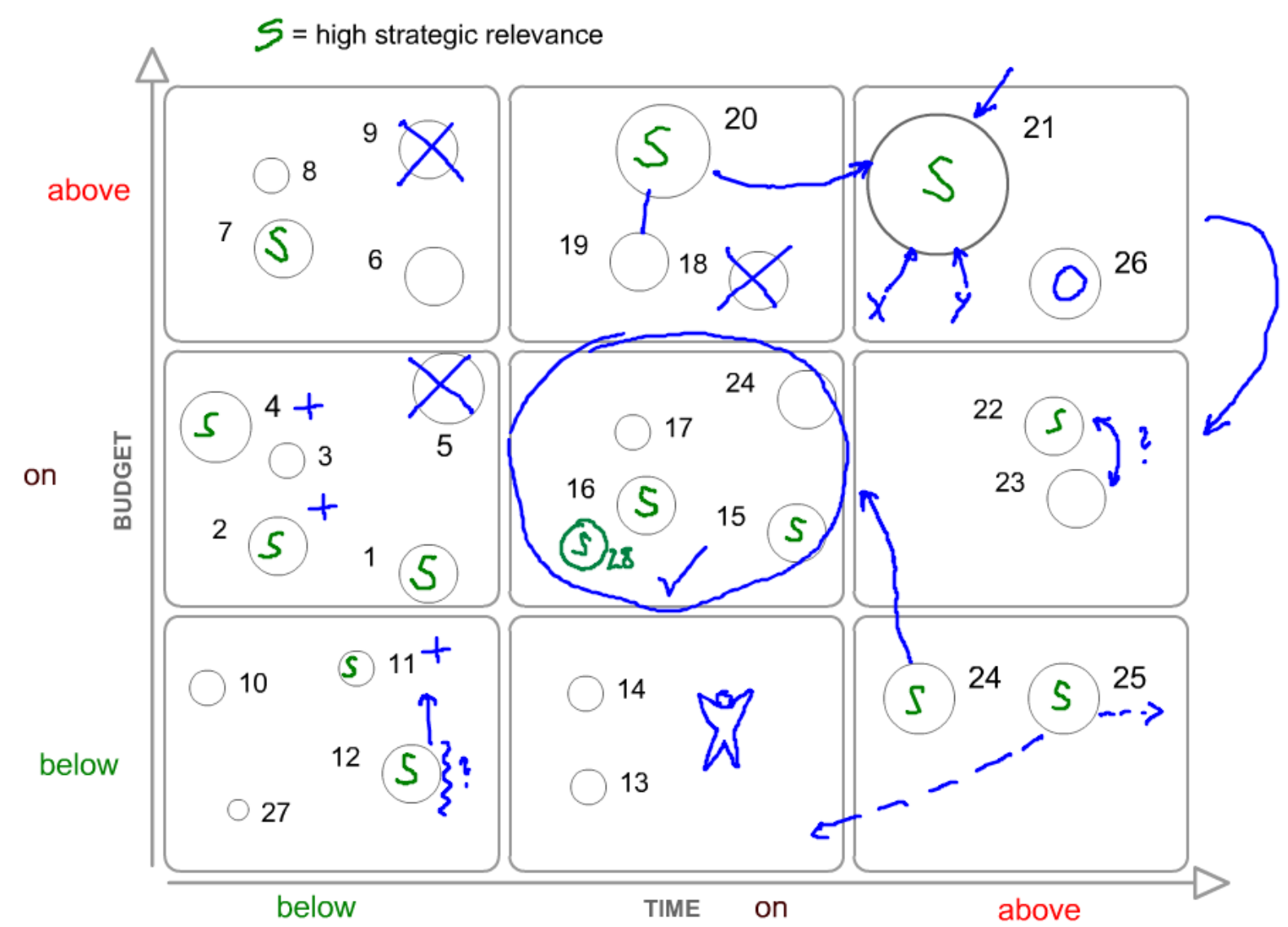

Figure 2: An example of sketchmarks on a multi-project review diagram

As a final result, the participants are not only more confident about their project funding decisions, but also feel more committed to their final decisions, as they were reached in a collaborative and engaged manner. In additions a photograph of the annotated chart serves as a handy reminder of the key arguments and deliberations. 
These two short scenarios can illustrate the numerous direct benefits of sketchmarks for managerial decision making. In the next section, we outline the vocabulary of this simple visual language by presenting a classification of sketchmarks for chart annotation.

\section{Scenario 3: A Sales Management Meeting}

Most project meetings, especially the ones with only a few participants, take place without any interactive support. Instead, all team members bring their own set of printed slides to the meeting and usually take their own notes during the meeting by highlighting and sketching directly on the slides. As they only can look at a single slide at once, the discussions always focus on the micro-perspective of the current slide. Obviously, in this setting, it is quite demanding for participants, to acquire a holistic view and to grasp an issue in its full complexity.

In the following scenario, a sales manager gets together with his subordinates. The objective of the meeting is to get a deeper insight and understanding into the sales figures for the company's different product lines. Based on the gained knowledge, the team will have to decide for which products they will increase marketing activities, and as the case might be, which products they eventually have to take out of their range of goods. The preparation has mainly been done by the department controllers and consists of a comprehensive slide deck displaying stacked bar charts, showing the cumulated sales per month and sales figures for every product.

In order to increase the performance of the meeting the team has two alternatives to the common usage of slide decks: The team members either spread all printed slides on the table or they stick them on a blank flip chart. In this scenario we decide in favor of the latter.

Instead of only focusing on a single chart, they now get a more general view on the presentation. The facilitator kicks-off the meeting with the first slide which contains the general overview (the center slide below). In this example, he starts with a stacked bar chart, showing the total revenue for all four product groups. The stacked bar chart does a very good job in terms of showing aggregated figures, but the so called floating baseline impedes comparison of the development over time for the single values. While continuing with the presentation he drapes the more detailed slides and charts around the overview slide. By talking about detailed slides we mean the kind of slide where only the development of revenue for the last twelve months is displayed (the four slides place around the central one below). These overviews per product are very useful to focus on a specific product group. They easily visualize trends, anomalies and patterns.

Bit by bit, the participants shift from a macro level view to the micro level perspective. At the same time, the facilitator and all participants also take advantage of the sketchmark technique: They use the same sketchmarks as described in example 1 above. In addition to only seeing the development of the single product groups, they can also identify dependencies between product groups or compare patterns and trends across all the goods 
they sell. They can also play with the charts and run through "what if" scenarios and assess the impact on other product group's revenue as well as on the total revenue.

At the end of the meeting, the participants feel, as in the scenarios described before, more committed to the decisions they have made. In addition, their decision also is of higher quality as they were able to take it based on the holistic view of the discussed issue. This example, unlike the two before, illustrates the fact that sketchmark-based discussions do not just have to be held around one single slide or chart, but can in fact encompass a series of inter-related graphics that can even be connected through sketchmarks (see figure below).

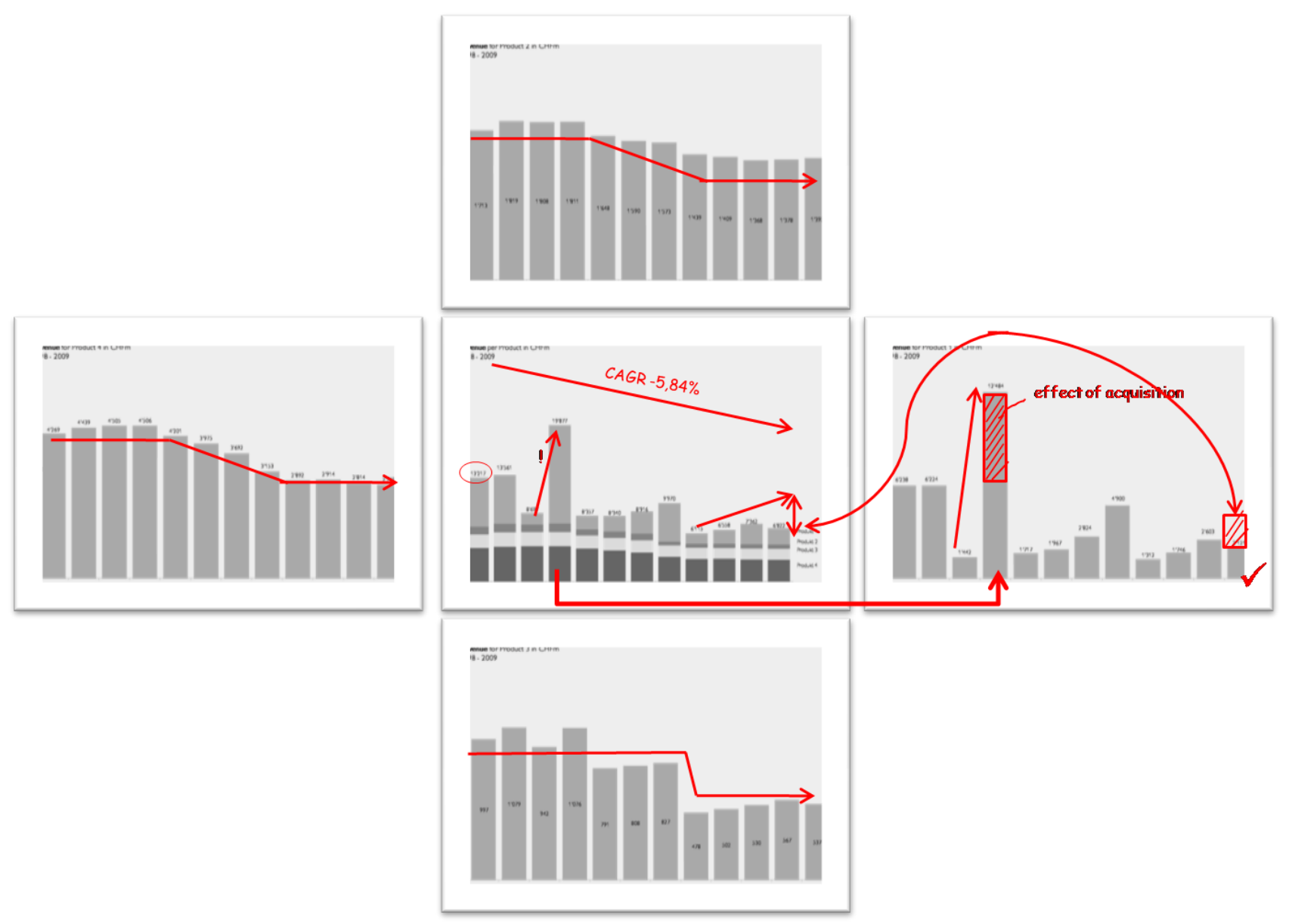

Figure 3: An example of sketchmarks used on multiple slides draped on a flipchart

Having given three examples of the use of skethcmarks in business contexts, the following box summarizes the use of sketch-based annotations on geographic maps. This is a frequent practice in the armed forces. 


\section{The Use of Sketchmarks in the Military}

Sketching provides a natural means of interaction for many spatially-oriented tasks. Such a task can be found in the military, more specifically when military planners are formulating battle plans, called Courses of Actions (COAs). The nature of those plans demands for a standardized vocabulary. A sketch is the most appropriate tool because it can be used whenever existing maps are not adequate, nor available (e.g. for operations in unknown terrain), or to illustrate findings from a reconnaissance or a patrol report. The COA basically consists of a sketch and a textual statement and thus conveys a number of crucial properties of the situation and the plan (Forbus, Usher, \& Chapman, 2003). The approach to formulate such a COA is as follows: After having analyzed the terrain, a depiction of the terrain features that are considered important is drawn, either on overlays on the maps, or on the basic terrain description itself. The result of this step is the identification of possible paths for movement (mobility corridors, avenues of approach) and good locations for different kinds of operations. The object in view and the amount of detail required to be shown determines the scale of the sketch. Troops and weapons, as well as vital infrastructures are illustrated by means of unit symbols, an elaborate vocabulary of graphical symbols defined as part of an army's doctrine (to simplify collaboration between different alliances, they are standardized in the western world). Friendly and own forces and actions are shown in blue ink, whereas what is known about the enemy forces is drawn in red ink. This graphical vocabulary also includes a limited number of symbols for tasks.

The military vocabulary consists of three dimensions: The type of unit (e.g., armor, infantry, etc., friendly, neutral and enemy), the echelon (e.g., corps to squad), and strength (regular, plus, minus, or a percentage). Every military symbol or tactical sign can be combined as needed, using those dimensions.

The spatial position and extend is a crucial part of the meaning of the visuals used in map-based sketches (Forbus et al., 2003). To illustrate this, just think of the position of a road or a path taken through complex terrain. The position or the size of those glyphs is depending on the type. Five different kinds of glyphs (basic skethcmarks) are commonly differentiated:

1. Location glyphs: Military units are an example of location glyphs: While their position matters doesn't the size of the box give any indication about the unit's strength or exact position and distribution.

2. Line glyphs: Roads and rivers are examples of line glyphs: Although their width is eminent they are simply drawn as lines without taken into account their width explicitly.

3. Region glyphs: Examples of region glyphs include terrain types (e.g., mountains, lakes, glaciers etc.) and designated areas (e.g., objective areas, battle positions, engagement and preparation areas, etc.) For those kinds of glyphs, both the exact location and boundary are important.

4. Path glyphs differ from line glyphs in that their width is considered to be significant, and they have a designated start and end. Several different types of paths are distinguished, for example, main attacks use a double-headed arrow, planned or alternative attacks use a dashed arrow, while supporting-attacks use a single headed arrow. The figure below illustrates different kinds of attacks. The figure also illustrates how a glyph can be varied to designate different kinds of activities.

5. Symbolic glyphs finally are mainly used to display abstract entities such as military tasks. For example a barrier is drawn around the place being defended. 


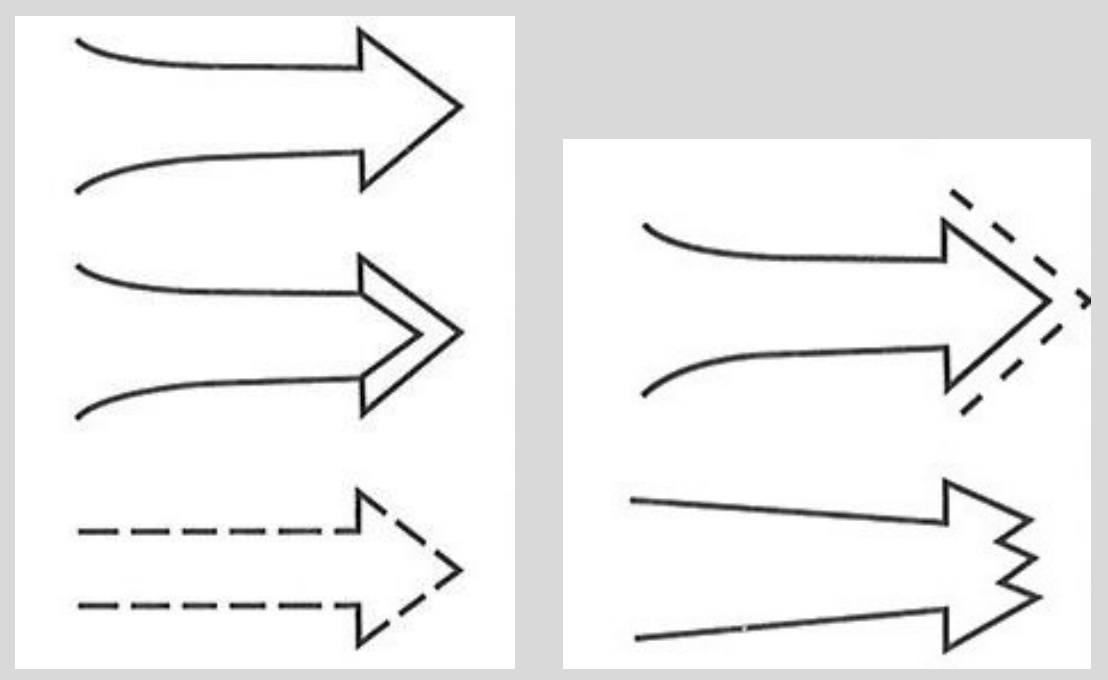

Figure 4: Variations of the path glyph attack symbol (side attack, main attack, planned attack, fake attack, aborted attack)

As military planning is in the majority of cases done under great uncertainty, commanders may ask their staff for alternative hypotheses about what could happen and how to respond. To display alternatives or sequences, the use of so called comic graphs is quite common. Like a comic strip, each sub-sketch, displaying a distinct state of affairs, leads to the next (Forbus \& Usher, 2002). The relationships between states are indicated by drawing arrows, labeled with the semantics of the relationship (e.g., hypothesis, intended next state, alternatives, etc.).

Sequences of sketches also allow for comparisons, which is an important operation on sketches (Gross \& Do, 1995). Those comparisons can be used to reflect on alternate choices, and to hypothesize enemy intent. 


\section{A Classification of Sketchmarks in Chart Annotation}

The first step towards understanding anything is to develop a classification. Herbert A. Simon

Having highlighted and exemplified the numerous benefits of using sketchmarks in management meetings, we now provide a classification of the various sketchmarks that managers can use to add meaning to charts under discussion.

Although sketching has received attention in various research fields, such as psychology, engineering, design, art history, education, or computer science (Mayer 2008, McGown \& Green 1998, Buxton 2007), the topic has not been discussed extensively in management literature. Dan Roam's (2009) recent bestseller on the topic is a notable exception. It relies, however, primarily on anecdotal evidence and does not discuss sketching for annotation at all (for an exception in another area see Landay 1995). A solid first step to improve our understanding of sketch-based annotations thus consists of trying to capture and distinguish the different types of annotations possible in a management meeting context. ${ }^{5}$

Existing classifications of sketches in other domains do not explicitly distinguish sketches that are self-contained (i.e., drawn or elicited from scratch) from those that are used as graphic annotations (although Buxton (2007) dedicates a chapter of his book to annotating sketches through sketches). We have only found three classifications of sketches in general ${ }^{6}$, two from the domain of design (Ferguson, 1992 and Verstijnen et al., 1998), and one from the domain of psychology (Mayer 2008).

Mayer (2008, p. 28) distinguishes logical or conceptual sketches from metaphorical sketches and configurational sketches. Logical sketches use typical diagram forms such as Venn or box and arrow diagrams. In the case of metaphoric sketches people use familiar images such as bridges, abysses, tunnels, mountains, or the weather to express ideas or insights. Configurational sketches represent people and their mutual relationships (or barriers for relationships). In another context (innovation management), Gray et al. (2010) come up with a similar distinction: they distinguish metaphorical or emotional sketches, diagrammatic or analytical sketches, and pragmatic or people-in-action depicting sketches.

While Mayer focuses on the sketching content as a classification principle, Verstijnen et al. (1998) focus on the function of a sketch and distinguish idea sketches from presentation

\footnotetext{
${ }^{5}$ We have already introduced another classification earlier in this article, namely the distinction between artistic, technical, and analytic sketches. While artistic or technical sketches may also be relevant in certain management contexts, they are not the focus of the present investigation, as we focus on data-driven managerial decision making.

${ }^{6}$ We have found other classifications of sketches in the literature, but they tend to focus on sketching for a specific technical, artistic, or administrative domain. An example of such a specific sketch classification is the one presented by Sweeney (2009) in his short book on sketching methods in the geographic mapping context.
} 
sketches (p. 520). ${ }^{7}$ While Idea sketches are drawn to generate ideas and develop new perspectives, presentation sketches are drawn to convey ideas to other people.

Probably the most noted classification of sketches - which is also based on the function of a sketch rather than its content - has been developed by Ferguson (1992). He has identified three kinds of sketches used collaboratively in the engineering context:

(1) The thinking sketch which engineers use to focus and guide nonverbal thinking;

(2) The prescriptive sketch made by an engineer to direct a draftsman in making a finished drawing;

(3) The talking sketch, produced during exchanges between technical people in order to clarify complex and possibly confusing parts of the drawing (see also McGown \& Green, 1998, p.436, for this point).

In our specific context of sketching as an annotation practice in management, we focus on the third type of sketch and distinguish further types within this group of 'talking sketches'.

We have chosen two main classification attributes to cluster and organize these 'talking sketches' or sketchmarks: the scope of a sketch annotation - that is to say whether it regards a single item in a chart or many - and if the sketch is used to merely highlight an item or to actually modify or change it (the intention of the sketch).

These two attributes gives us the axis for the classification of sketchmarks in the chart annotation context. While the scope refers to the object or ' $w h a t$ ' of sketching, the intention designates the ' $w h y$ ' or purpose of the sketching action (see Figure 3).

\footnotetext{
${ }^{7}$ Goldschmidt (1991, p.123) also seems to make this distinction, although she only refers to what she calls 'study sketches' (which are very similar to the notion of idea sketches).
} 


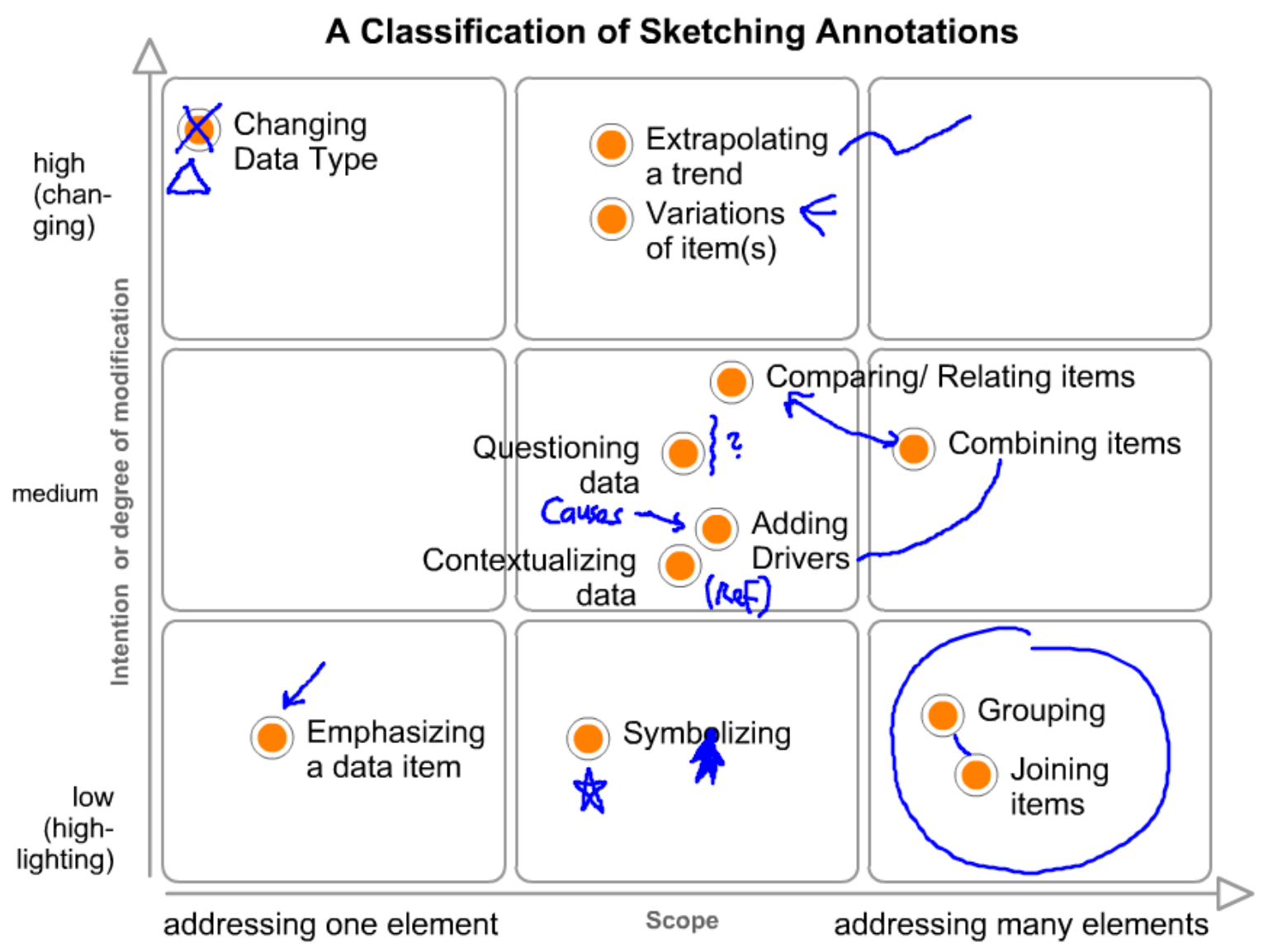

Figure 5: A tentative classification of sketch marks in chart annotation

This current classification is tentative in the sense that is more conceptual than empirically derived. Clearly, there may be many other annotation acts that can contribute to a joint understanding of decision-relevant data in management meetings. Anyway, having empirically identified a first set of useful sketchmarks for the business context, certainly laid the groundwork for a more significant, new language and could be the first step towards a powerful language and manner of communicating.

In Table 1 in the appendix we provide a list of such sketchmarks and briefly describe each one. Table 2 in the appendix lists a few of the guidelines managers can follow when using such sketchmarks for collaborative decision making in their daily practice.

\section{Conclusion and Outlook}

People know what they think when they see what they say. Karl E. Weick

Saying things with sketch annotations is an unusual, but highly effective way of supporting the joint interpretation of data in management teams. Using this approach does not require highly sophisticated design know-how, nor does it have to rely on a costly infrastructure. Sketch-based annotations are a natural "third way" besides static, one-way slide presentations and unsystematic, fleeting conversations. Sketch-based annotations combine 
the simplicity and immediacy of drawing with the clarity and richness of charting. To make use of this value, managers should follow a few simple guidelines summarized in the second table in the appendix. This ensures that sketching is used appropriately as a collaborative communication and annotation practice.

Still, the use of ad-hoc sketchmarks for decision support in management meetings is a largely unexplored research topic. In our own research we are preparing experimental studies to systematically evaluate the benefits and risks of this visual management practice. These experiments should reveal whether sketching support in deed increases the process and result quality of management decision meetings and can lead to consistently higher decision quality. This research can also provide us with insights of which types of sketchmarks provide the greatest benefits for managerial decision making. As an additional result of these experiments, we hope to develop more complex sketching patterns that can be used in complex problem solving and deliberation.

In addition to gathering experimental evidence, we would also like to gather context-rich case study evidence of how chart annotation can improve management meetings in real-life organizations. We will furthermore examine the role of electronic (and blended) sketching and in how far this collaborative practice differs from paper-based sketching. In this context, we will also examine the usefulness of 'sketch replay' or in other words the benefits to managers of being able to record and review the development of certain sketches on a screen. ${ }^{8}$

Managers can use our tentative classification to identify useful sketchmarks for their own meetings and workshops (the tables in the appendix can provide further pointers to this regard). They can experiment with this new visual vocabulary and in doing so move away from static, monologue-like presentations or data-free, ephemeral conversations to productive, interactive, illuminating, and persistent chart discussions.

\footnotetext{
${ }^{8}$ Tools such as Adobe Connect or www.papershow.com and various screen recording applications (such as the free CamStudio screen recorder) are able to capture not just the sketches as end results themselves, but also their step-by-step development process or their history. In this way all sketching actions are recorded in the proper sequence. Electronic, sketch-based chart annotation by multiple participants can also be easily implemented using PowerPoint or lets-focus and the free Teamplayer software (for multi-pointer support) at wunderworks.com.
} 


\section{References}

Anderson, R. E., Helstrup, T. (1993) Visual discovery in mind and on paper, Memory and Cognition, 21(3), 283-293.

Blackwell, A., Church, L., Plimmer, B., Gray, D. (2008) Formality in Sketches and Visual Representation: Some Informal Reflections, in: Plimmer, B., Hammond, T. (Eds.) Proceedings of the VL/HCC Workshop, Herrsching am Ammersee, Germany, 11-18.

Bohm, D. (2000) On Dialogue. 3rd edition. New York: Routledge.

Bresciani S., Blackwell A.F., Eppler M. (2008) A Collaborative Dimensions Framework: Understanding the Mediating Role of Conceptual Visualizations in Collaborative Knowledge Work. Proceedings of the 41st Hawaii International Conference on System Sciences (HICSS 2008). Hawaii: IEEE Press.

Buxton, B. (2007) Designing the User Experience. New York: Morgan Kaufmann.

Duarte, N. (2008) Slide:ology. Sebastopol, CA: O’Reilly.

Eppler, M.J., Mengis, J., Bresciani, S. (2008) Seven Types of Visual Ambiguity: On the Merits and Risks of Multiple Interpretations of Collaborative Visualizations, in: Proceedings of the 12th International Conference on Information Visualization IVO8, London: IEEE Press.

Ferguson, E.S. (1994) Engineering and the Mind's Eye. Cambridge, MA: MIT Press.

Fish, J., Scrivener, S. (1990) Amplifying the mind's eye: Sketching and Visual Cognition. Leonardo, (23) 1, 117-126

Forbus, K. D., \& Usher, J. (2002). Sketching for knowledge capture: a progress report. Paper presented at the Proceedings of the 7 th international conference on Intelligent user interfaces.

Forbus, K. D., Usher, J., \& Chapman, V. (2003). Sketching for Military Courses of Action Diagrams. Paper presented at the Proceedings of IU'03, Miami, Florida.

Goldschmidt, G. (1991) The Dialectis of Sketching, Creativity Research Journal, 4(2), 123-143.

Gray, D., Brown, S., Macanufo, J. (2010) Gamestorming: A Playbook for Innovators, Rulebreakers, and Changemakers. Sebastopol, CA: O’Reilly.

Gross, M., \& Do, E. (1995). Drawing Analogies - Supporting Creative Architectural Design with Visual Reference. Paper presented at the 3rd International Conference on Computational Models of Creative Design, Sydney.

Heiser, J., Tversky, B., Silverman, M. (2004) Sketches for and from collaboration. Retrieved online at: http://psychology.stanford.edu/ bt/gesture/papers/ [December $21^{\text {st }} 2009$ ] 
Henderson, K. (1991) Flexible Sketches and Inflexible Data Bases: Visual Communication, Conscription Devices, and Boundary Objects in Design Engineering. Science, Technology \& Human Values, (16) 4, 448-473.

Isaacs, W. (1997) Dialogue and the art of thinking together: A pioneering approach to communicating in business and in life. New York: Doubleday.

Landay, J.L. (1995) Interactive sketching for the early stages of user interface design. PhD Thesis. School of Computer Science. Carnegie Mellon University.

Mayer, C. (2007) Hieroglyphen der Psyche: Mit Patientenskizzen zum Kern der Psychodynamik. Berlin: Stuttgart. [Hieroglyphics of the psyche: getting to the core of psychodynamics through patients' sketches]

McGown, A., Green, G. (1998) Visible ideas: information patterns of conceptual sketch activity, Design Studies, 19 (4), 431-453.

Pfeffer, J., \& Sutton, R. I. (2006). Evidence Based Management. Harvard Business Review (January 2006), 63-74.

Roam, D. (2009) Back of the Napkin: Solving Problems and Selling Ideas with Pictures. New York: Penguin Books.

Sweeney, W.C. (2009) Sketching Methods. Originally published in 1917. Charleston: Bibliolife.

Tversky, B. (2002) What do sketches say about thinking. 2002 AAAl Spring Symposium. Retrieved online at: http://www.aaai.org/Papers/Symposia/Spring/2002/SS-02-08/SS02-08022.pdf [December $21^{\text {st }} 2009$ ]

Tversky, B, Zacks, J., Lee, P. U., \& Heiser, J. (2000) Lines, blobs, crosses, and arrows: Diagrammati communication with schematic figures. In M. Anderson, P. Cheng, and V. Haarslev eds., Theory and application of diagrams. Berlin: Springer-Verlag, 221-230.

Tversky, B., Masaki, S. (2009) Thinking with Sketches. In: Markman, A.B., Wood, K.L. (Eds.) Tools for Innovation: The Science behind the practical methods that drive innovation. Oxford: Oxford University Press.

Verstijnen, I.M., Hennessey, van Leeuwen, C., Hamel, R. (1998) Sketching and creative discovery, Design Studies, 19 (4), 519-546. 


\section{Appendix}

Table 1: Examples of sketchmarks to be used in management meetings

\begin{tabular}{|c|c|c|}
\hline $\begin{array}{l}\text { Sketch- } \\
\text { mark } \\
\text { Action }\end{array}$ & Description & Example \\
\hline Delete & $\begin{array}{l}\text { Documentation of a management team's } \\
\text { decision to eliminate or discard an } \\
\text { element or option. }\end{array}$ & \\
\hline $\begin{array}{l}\text { Work- } \\
\text { around }\end{array}$ & $\begin{array}{l}\text { Documentation of a work-around idea } \\
\text { how to overcome a problem or challenge. }\end{array}$ & \\
\hline Group & Group elements into a higher-level whole. & \\
\hline $\begin{array}{l}\text { Empha- } \\
\text { size }\end{array}$ & $\begin{array}{l}\text { Highlight an element currently under } \\
\text { discussion. }\end{array}$ & \\
\hline $\begin{array}{l}\text { Connect } \\
\text { or } \\
\text { compare }\end{array}$ & $\begin{array}{l}\text { Put two items into a relationship with one } \\
\text { another. }\end{array}$ & Eler \\
\hline $\begin{array}{l}\text { Question } \\
\text { / Doubt }\end{array}$ & $\begin{array}{l}\text { A curved vertical line indicates doubts or } \\
\text { uncertainties regarding a particular item } \\
\text { or element. }\end{array}$ & $\left\{\begin{array}{l}\text { Item } \\
\text { or } \mathrm{E}\end{array}\right.$ \\
\hline $\begin{array}{l}\text { Distin- } \\
\text { guish }\end{array}$ & $\begin{array}{l}\text { A single item is split into various types or } \\
\text { facets. }\end{array}$ & \\
\hline $\begin{array}{l}\text { Extrapo- } \\
\text { late }\end{array}$ & $\begin{array}{l}\text { Extending a current trend into the future } \\
\text { or into different possible scenarios. }\end{array}$ & \\
\hline Resize & Changing the scope of an item or element. & \\
\hline $\begin{array}{l}\text { Symbo- } \\
\text { lize }\end{array}$ & $\begin{array}{l}\text { Placing icons or symbols to add meaning } \\
\text { to elements. }\end{array}$ & Elemen \\
\hline Vote & $\begin{array}{l}\text { Adding sketchmarks to indicate } \\
\text { preferences or priorities. }\end{array}$ & $\begin{array}{l}\text { Element 1 } \\
\text { Element 2 } \\
\text { Element 3III }\end{array}$ \\
\hline Check & $\begin{array}{l}\text { Adding this sketchmark indicates that the } \\
\text { checked item or element has been } \\
\text { discussed verified, decided, or simply } \\
\text { dealt with. }\end{array}$ & Element $\mathrm{X}$ \\
\hline
\end{tabular}




\begin{tabular}{|l|l|l|}
\hline Hatch & $\begin{array}{l}\text { Highlight a particular area in a chart or } \\
\text { diagram. }\end{array}$ & $\begin{array}{l}\text { Element 1 } \\
\text { Element 4 }\end{array}$ \\
\hline Combine & $\begin{array}{l}\text { Bringing toment 2 } \\
\text { elements that share certain properties or } \\
\text { lead to a common consequence. }\end{array}$ \\
\hline $\begin{array}{l}\text { Re- } \\
\text { classify }\end{array}$ & $\begin{array}{l}\text { Change the category of an item in a chart } \\
\text { by changing its symbol. }\end{array}$ \\
\hline Tag & $\begin{array}{l}\text { Adding a letter or symbol to tag special } \\
\text { items in a chart. }\end{array}$ \\
\hline Move & $\begin{array}{l}\text { Changing the positioning of an element, } \\
\text { for example in a matrix or portfolio chart. }\end{array}$ \\
\hline Simplify & $\begin{array}{l}\text { Simplify a complex structure or pattern by } \\
\text { emphasizing extreme values or turning } \\
\text { points. }\end{array}$ \\
\hline
\end{tabular}


Table 2: Guidelines for the use of sketchmarks in management meetings ${ }^{9}$

\begin{tabular}{|c|c|}
\hline Guidelines & Implementation Examples \& Comments \\
\hline \multicolumn{2}{|l|}{ Before the Meeting } \\
\hline $\begin{array}{l}\text { Carefully review the charts to be presented } \\
\text { during the meeting and pick the most important } \\
\text { or informative ones to be jointly discussed and } \\
\text { annotated. }\end{array}$ & $\begin{array}{l}\text { Charts that lend themselves to joint visual } \\
\text { discussions are comparison charts or timelines } \\
\text { (see the example section of the article). }\end{array}$ \\
\hline $\begin{array}{l}\text { Make sure that sufficient pens are available in } \\
\text { different colors. }\end{array}$ & $\begin{array}{l}\text { Useful pen colors for subsequent color-coding of } \\
\text { chart annotations are blue for comments, red to } \\
\text { point out risks or signal criticism, green for } \\
\text { positive points, and orange for general } \\
\text { highlighting or focusing. Alternatively different } \\
\text { colors can be assigned to different meeting } \\
\text { participants. }\end{array}$ \\
\hline $\begin{array}{l}\text { Print the charts that are to be discussed in large } \\
\text { format, but not on glossy paper and not in a very } \\
\text { polished style (otherwise participants feel } \\
\text { reluctant to add sketchmarks). }\end{array}$ & $\begin{array}{l}\text { Charts to be jointly annotated can be printed on } \\
\text { A3 paper and pasted to flip charts for smaller } \\
\text { groups (i.e., 1-4 people) or plotted out on a } \\
\text { larger poster for larger groups (i.e., five or } \\
\text { more). Alternatively large multi-touch screens or } \\
\text { whiteboards can be used for up to } 10 \\
\text { participants. }\end{array}$ \\
\hline \multicolumn{2}{|l|}{ During the Meeting } \\
\hline $\begin{array}{l}\text { Assemble the meeting participants close to the } \\
\text { chart so that it can be read and annotated easily. }\end{array}$ & $\begin{array}{l}\text { Have the participants form a semi-circle around } \\
\text { a flip chart or brown paper poster or around the } \\
\text { multi-touch screen. }\end{array}$ \\
\hline $\begin{array}{l}\text { Make sure that all participants have access to } \\
\text { the chart that is annotated and that everybody } \\
\text { has a pen or device to make annotations. }\end{array}$ & $\begin{array}{l}\text { Use a large poster version of a chart instead of } \\
\text { simply pasting a print-out on a flipchart. }\end{array}$ \\
\hline $\begin{array}{l}\text { Structure the annotation process into } \\
\text { reasonable phases. }\end{array}$ & $\begin{array}{l}\text { Begin with overall comments or annotations } \\
\text { before entering into details. }\end{array}$ \\
\hline $\begin{array}{l}\text { Ensure that the meaning of each sketchmark is } \\
\text { clear to all participants. }\end{array}$ & $\begin{array}{l}\text { Ask participants to elaborate on the meaning of } \\
\text { symbols that may be unclear or ambiguous. }\end{array}$ \\
\hline $\begin{array}{l}\text { Ensure respectful annotations and modifications } \\
\text { among all participants. }\end{array}$ & $\begin{array}{l}\text { Some participants may feel offended if their own } \\
\text { sketchmark contributions are erased or modified } \\
\text { without prior notice or without a short mutual } \\
\text { check among them. }\end{array}$ \\
\hline \multicolumn{2}{|l|}{ After the Meeting } \\
\hline $\begin{array}{l}\text { Take a photograph of the annotated chart if the } \\
\text { participants worked manually on a flip chart or } \\
\text { paper. }\end{array}$ & $\begin{array}{l}\text { Taking a digital photograph of an annotated } \\
\text { chart and sending it to all participants right after } \\
\text { the meeting helps to remember the discussion } \\
\text { and its results and creates momentum for } \\
\text { subsequent implementation steps. }\end{array}$ \\
\hline $\begin{array}{l}\text { If feasible, annotate the sketchmarks with } \\
\text { explanatory mouse-over comments for an } \\
\text { interactive documentation. For complex } \\
\text { annotations provide a digital replay function } \\
\text { (based on the prior recording) to show the } \\
\text { annotations step by step. }\end{array}$ & $\begin{array}{l}\text { If sketchmarks have been added digitally, then } \\
\text { mouse-over comments can be added right away. } \\
\text { For paper-based sketchmarks, side notes should } \\
\text { be taken and integrated into the chart digitally } \\
\text { later on. }\end{array}$ \\
\hline
\end{tabular}

\footnotetext{
${ }^{9}$ Further guidelines, examples, and instructions can be found at our youtube sketching channel at
} www.youtube.com/sketchology. 


\section{About the Authors:}

\section{Martin J. Eppler, Prof. Dr. sés.}

is a full professor of media and communications management at the University of St. Gallen (HSG), where he is also a director of the institute for media and communication management (www.mcm.unisg.ch). He conducts research on knowledge management, knowledge visualization, and knowledge communication. He has been a guest professor at various universities in Asia and Europe. He has been an advisor to organizations such as the United Nations, Philips, UBS, the Swiss Military, Ernst \& Young, KPMG, Swiss Re, Daimler and others. Martin J. Eppler studied communications, business administration and social sciences at Boston University, the Paris Graduate School of Management, and the Universities of Geneva (PhD) and St. Gallen (Masters). He has published more than 80 academic papers (in journals such as Organization Studies, LRP, Harvard Business Manager, IEEE Transactions, TIS, EMJ, IV, and others) and eight books, mostly on knowledge communication, management, and visualization.

\section{Roland Pfister, lic.oec. HSG}

is a $\mathrm{PhD}$ candidate at the University of St. Gallen, =mcminstitute, Institute for Media and Communication Management. He holds a degree in business for small and medium sized enterprises from the University of St. Gallen. After finishing his diploma thesis on human resources management, he has worked for two years as an IT consultant in the field of core banking applications for Accenture, a major consulting company, and another two years as a Senior Business analyst for Credit Suisse. In his research, he examines the impact of (quantitative) visualization on communication in management processes. 